\title{
Bowel Obstruction
}

National Cancer Institute

\section{Source}

National Cancer Institute. Bowel Obstruction. NCI Thesaurus. Code C9175.

Blockage of the normal flow of the intestinal contents within the bowel. 